\title{
Grupo de Maracatu na universidade: práticas culturais juvenis e autoformação
}

\author{
Grupo Maracatu en la universidad: prácticas culturales juveniles y \\ autoformación
}

Maracatu group at university: youth cultural practices and self-training

\author{
Luís Antonio Groppo ${ }^{1}$ \\ Giovana Generoso Monteiro ${ }^{2}$
}

\begin{abstract}
Resumo
Por meio de observação participante e entrevistas semiestruturadas, são analisadas as práticas culturais juvenis e os processos formativos de um grupo percussivo de Maracatu composto por estudantes de uma universidade pública de Minas Gerais. O objetivo é conhecer as práticas de formação política e cultural vividas pelo grupo, via o cultivo de tradições oriundas do Maracatu Nação pernambucano. São debatidos os dilemas enfrentados pelo grupo, diante de questões de gênero e das relações com a tradição e a religiosidade. Os resultados destacam a riqueza das práticas autoformativas e autogestionárias do grupo universitário, as quais constituem processos de subjetivação de grande potência cultural e política.
\end{abstract}

Palavras-Chave: Cultura popular; Juventude; Autogestão; Universidade.

\section{Resumen}

Por medio de observación participante y entrevistas semiestructuradas, se analizan las prácticas culturales juveniles y los procesos formativos de un grupo percusionista de Maracatu composto por estudiantes de una universidad pública de Minas Gerais. El objetivo es conocer las prácticas de formación política y cultural vividas por el grupo, a través del cultivo de tradiciones oriundas del Maracatu Nación pernambucano. Se discuten los dilemas enfrentados por el grupo, ante cuestiones de género y de las relaciones con la tradición y la religiosidad. Los resultados destacan la riqueza de las prácticas autoformativas y autogestionarias del grupo universitario, que constituyen procesos de subjetivación de gran poder cultural y político.

Palabras claves: Cultura popular; Juventud; Autogestión; Universidad.

\begin{abstract}
Through participant observation and semi-structured interviews, we analyze the youth cultural practices and the formative processes of a percussive group of Maracatu, made up of students from a public university in Minas Gerais. The objective is to know the practices of political and cultural formation lived by group, through the cultivation of traditions from the Maracatu Nation of Pernambuco. The dilemmas faced by the group are discussed, in the face of gender issues and relations with tradition and religiosity. The results highlight the richness of the self-training and self-management practices of the university group, which constitute subjectivation processes of great cultural and political power.
\end{abstract}

\footnotetext{
${ }^{1}$ Doutor em Ciências Sociais pela Universidade Estadual de Campinas (Unicamp); Professor da Universidade Federal de Alfenas (UNIFAL-MG); Alfenas, Minas Gerais, Brasil; luis.groppo@unifal-mg.edu.br.

${ }^{2}$ Graduanda em Licenciatura em História pela Universidade Federal de Alfenas (UNIFAL-MG); Alfenas, Minas Gerais, Brasil; giovanageneroso100@gmail.com.
} 
Keywords: Popular culture; Youth; Self-management; University.

\section{Introdução}

Encantamento e estranhamento costumam ser os sentimentos mais comuns quando se tem um primeiro contato com o grupo de Maracatu na universidade. Encantamento pela força rítmica, pelo compasso firme e harmônico de contratempos marcantes e pela beleza do balanço dos corpos. Estranhamento diante do som muito alto, dentro de um ambiente do qual se costuma esperar silêncio compenetrado, e do fato de que uma roda formada quase que somente por mulheres universitárias (na maioria das vezes, só por elas), com brancas formando uma pequena maioria, reproduza uma manifestação cultural de origem nordestina associada às comunidades populares e negras de Pernambuco - aqui no interior de Minas Gerais.

O contato com a literatura sobre o Maracatu nem sempre finda com esse estranhamento, como quando, não sem justiça, pesquisas tratam das apropriações desta manifestação originalmente popular, comunitária e complexa (envolvendo percussão, dança, coreografia, ciclo de festas e religiosidade) por jovens brancas e brancos de classe média (KOSLINSKI, 2011; LIMA, 2014; SOUZA, 2006). Outras tratam da sua transformação em mercadoria pela grande mídia, indústria cultural e o turismo comercial (CARVALHO, 2007; OLIVEIRA, 2011). Há aquelas, ainda, que consideram que as relações dos diferentes grupos sociais e da indústria cultural com o Maracatu são complexas, com diversas sutilezas e possibilidades de resistência e criatividade (GARCEZ, 2013; MEDEIROS, 2003; SILVA, 2004; UCELLA; LIMA, 2013). Qual seria o significado, ou significados, dessa recriação do Maracatu de Baque Virado - ou Nação - pernambucano tão longe de sua terra natal, de seus lugares de encenação tradicionais, por sujeitos de outras classes e etnia, composto majoritariamente por mulheres em vez da hegemonia masculina? Seria realmente uma apropriação empobrecedora e descontextualizada, ou ainda, orientada tão somente pelo mercado de entretenimento e o circuito de espetáculos?

Essas questões tiveram que, obrigatoriamente, ser consideradas como parte do esforço de compreensão do que era o objetivo inicial da investigação que deu origem a este texto. $\mathrm{O}$ objetivo inicial, ainda mantido, é o de analisar a dimensão educativa não formal e os processos de formação política ensejados pelos coletivos juvenis na universidade pública mineira. ${ }^{3}$ Atender a esse objetivo demandava, necessariamente, passar pela questão que nos

\footnotetext{
${ }^{3}$ A pesquisa A dimensão educativa das organizações juvenis: Estudo dos processos educativos não formais e da formação política no interior de organizações juvenis de uma universidade pública do interior de Minas Gerais
} 
leva a conectar o local (um pequeno grupo percussivo de Maracatu universitário) e o particular (processos específicos de formação cultural e política) a um cenário mais amplo (o universo do Maracatu) e a processos históricos e culturais mais largos (o revigoramento do Maracatu pernambucano nos anos 1990, sua complexa relação com a indústria cultural e o turismo, e as releituras do Maracatu quando levado para outros grupos sociais e regiões do país e até mesmo ao exterior).

Sobre a educação não formal, na busca de um conceito para ela, Fernandes e Park citam Afonso para distinguir o formal e o não formal:

Por educação formal entende-se o tipo de educação organizada com uma determinada sequência (prévia) e proporcionada pelas escolas, enquanto que a designação não formal, embora obedeça a uma estrutura e a uma organização (distintas, porém das escolas) e possa levar a uma certificação (mesmo que não seja essa a finalidade), diverge ainda da educação formal no que respeita a não fixação de tempos e locais e a flexibilidade na adaptação aos conteúdos de aprendizagem a cada grupo concreto (ALFONSO apud FERNANDES; PARK, 2007, p. 131).

A educação não formal é tratada aqui menos como uma novidade ou como uma forma recente de educação, ou seja, como um tipo histórico, mas, antes, como um tipo ideal, no sentido atribuído por Max Weber (1979): um tipo de educação que tem intencionalidade, caráter não obrigatório, mistura de idades, flexibilidade de tempos e espaços, orientada para as necessidades dos grupos envolvidos, não apresentando hierarquização, não visando certificação e acontecendo por meio de metodologias variadas (GARCIA, 2007). Desta forma, pode nos ajudar a reconhecer processos formativos distintos dos escolares e dos informais, atuando em diversos espaços e tempos sociais, inclusive à sombra das instituições escolares, nos meandros dos processos formais de ensino-aprendizagem. Também, como nos ensina Valéria Aroeira Garcia (2009), não é preciso pensar o não formal em oposição ao formal. Tratam-se de distintos campos de formação humana, com diferentes formas, objetivos e preocupações, que não precisam se polarizar. Mas também, não se reduzem um ao outro.

foi coordenada pelo autor deste artigo e apoiada com Bolsa de Produtividade em Pesquisa pelo Conselho Nacional de Desenvolvimento Científico e Tecnológico (CNPq), bem como por Bolsas de Iniciação Científica pelo próprio CNPq e pela Fundação de Amparo à Pesquisa do Estado de Minas Gerais (FAPEMIG) e, também, por bolsas de Mestrado pelo Programa PIB-Pós da UNIFAL-MG e pela Coordenação de Aperfeiçoamento de Pessoal de Nível Superior (CAPES). Ela se realizou entre março de 2016 e fevereiro de 2019. Todo o processo de pesquisa foi assumido coletivamente pelo Grupo de Estudos sobre a Juventude da UNIFAL-MG, projeto que alia extensão e pesquisa, envolvendo estudantes da Universidade de diversas graduações e do Mestrado em Educação, assim como estudantes do Ensino Médio com bolsa de Iniciação Científica. Nas reuniões do grupo, debatemos o projeto de pesquisa, construímos o roteiro da entrevista, aplicamos a entrevista-teste e discutimos os resultados. Boa parte das análises aqui presentes surgiu desses debates. 
Neste sentido, como uma categoria de análise das relações educacionais, como um tipo-ideal, é que a educação não formal pode contribuir para compreender os processos de formação política e social proporcionados pelas organizações juvenis no interior das instituições de ensino superior. As organizações ou coletivos juvenis têm a intenção de ser espaço de participação e auto-organização de jovens estudantes, no campo político, cultural, religioso e esportivo, entre outros. Mas também, com diferentes graus de consciência e planejamento, esses coletivos são espaços de educação não formal, em atividades que proporcionam o aprendizado de ideias, valores, hábitos, habilidades e exercícios de cunho direta ou indiretamente político e cultural.

A coautora deste artigo realizou, durante sua Iniciação Científica (IC), observações e entrevistas com o grupo de Maracatu na universidade, ao longo de 2017. Ela havia participado, antes, de algumas oficinas desse grupo, mas quando retomou o convívio com o Maracatu para a investigação sofreu um grande estranhamento, em especial devido ao aprofundamento do grupo em relação aos aspectos religiosos do Maracatu. Ainda que tivesse amizade prévia com alguns membros do grupo, esse estranhamento permitiu à pesquisadora um distanciamento em relação ao que supostamente lhe era familiar, aproximando-a do que é chamado de observação participante, típica da pesquisa etnográfica.

Esta pesquisa, do ponto de vista empírico, privilegia dados qualitativos, ou seja, que tratam de experiências vividas por sujeitos em seu cotidiano e que revelam, antes, uma forma particular de viver as normas sociais e os valores culturais, em vez de tenderem a generalizações (ANDRE, 2009). Mais especificamente, é uma pesquisa de "tipo etnográfico", ou seja, uma pesquisa que, ainda que não tenha conseguido aplicar todas as exigências da etnografia tradicional em um contexto educacional, consegue vivenciar alguns de seus mais importantes atributos: faz uso das principais técnicas associadas à etnografia, a observação participante e a entrevista intensiva; há um grande grau de interação do sujeito pesquisador com a situação estudada; enfatizam-se antes os processos, em vez do produto ou resultados finais do fenômeno pesquisado; há grande preocupação em conhecer a visão de mundo dos sujeitos pesquisados, ou seja, como elas veem a si mesmas e o contexto onde estão inseridas; e há um tempo relativamente grande e intenso de convivência do sujeito pesquisador com os sujeitos pesquisados (ANDRE, 2009).

A observação participante, conforme tem se realizado na pesquisa, tende a seguir os passos sugeridos por Roberto Cardoso de Oliveira (2006), que enfatiza olhar, ouvir e escrever, de modo que a pesquisadora ou o pesquisador torna-se o principal instrumento de pesquisa, necessitando aguçar seus sentidos e percepções, bem como realizar um apurado registro 
etnográfico. Destacam-se os registros dos "estranhamentos" e das "experiências reveladoras", sem deixar de lado os aspectos rotineiros, isto é, a "prática" da Etnografia (MAGNANI, 2009).

Além da observação, a coautora realizou entrevistas semiestruturadas, as quais também privilegiam o qualitativo, mas tendem a destacar os aspectos pessoais, subjetivos, e a provocar a autorreflexão de quem a concede (SZYMANSKI, 2004). Se a observação participante enfatiza as práticas formativas, a entrevista parece desvelar os impactos e alguns dos resultados individuais destas práticas.

A partir das primeiras observações, foram definidas quais pessoas seriam convidadas para as entrevistas. Elas deveriam representar distintas formas de participação no coletivo e a diversidade dos seus membros. As 5 pessoas escolhidas foram entrevistadas ao longo de 2017. Elas assinaram um Termo de Consentimento Livre e Esclarecido e são identificadas por pseudônimos escolhidos pelo autor de modo aleatório: Tiago, professor da universidade, que criou o grupo em 2004 - foi seu primeiro coordenador e permaneceu no Maracatu até 2010; Juliana, estudante de Licenciatura em História, que entrou no grupo em 2012 e foi sua regente em 2016; Estela, estudante de Bacharelado em Geografia, membro do grupo desde 2016 e regente quando entrevistada; Pedrita, estudante de Licenciatura em Biologia, membro do grupo desde 2013 e Israel, estudante de Licenciatura em História, membro do grupo desde 2015.4

\title{
2. O Maracatu e as práticas culturais juvenis
}

Envolver-se com a bibliografia sobre as nações e os grupos de Maracatu significou ir ao encontro de importantes, mas complexas, discussões e reflexões acerca de cultura e de culturas: popular, negra, popular negra, afro-brasileira, nordestina e pernambucana. Uma interessante definição do Maracatu Nação é a de Anna Koslinski (2011):

\begin{abstract}
Maracatu-Nação ou "Maracatu de baque virado" é uma manifestação popular afrobrasileira com forte presença no Estado de Pernambuco. [...] em linhas gerais podese descrever o Maracatu-Nação como sendo uma manifestação que denomina um ritmo que é produzido por uma bateria ou batuque, composta apenas de instrumentos de percussão, e também a dança executada ao som desse batuque. [...] Geralmente as nações formam blocos de apresentação compostos pelos "batuqueiros" (percussionistas) e pelos dançarinos que encenam uma corte com rei, rainha, princesas, duques, vassalos, representando também personagens da cultura popular e
\end{abstract}

\footnotetext{
${ }^{4}$ A pesquisa A dimensão educativa das organizações juvenis foi aprovada pelo Comitê de Ética em Pesquisa da Universidade Federal de Alfenas (UNIFAL-MG), em 25 de junho de 2015, pelo Parecer n ${ }^{\circ}$ 1.092.498. Para fins de preservação dos sujeitos pesquisados, além de não serem revelados seus nomes verdadeiros, não se revela o nome do coletivo onde atuam, nem da universidade onde estudaram.
} 
religiosidade afro-indo-brasileira como caboclos arreamá, baianas e divindades do xangô e jurema (KOSLINSKI, 2011, p. 12).

Os Maracatus tradicionais do Recife se distinguem entre Maracatu Nação e Maracatu Orquestra. O Maracatu Orquestra, também chamado de Rural, tem outra constituição rítmica e instrumental: inclui, além dos instrumentos percussivos, instrumentos de sopro, e sua música é mais acelerada. Caracteriza-se também por ter um personagem central, o caboclo de lança (LIMA, 2014; MEDEIROS, 2003). Se o Maracatu nasceu em Pernambuco, logo se difundiu para outros estados do Nordeste ao longo do século XX, como Alagoas e, principalmente, o Ceará - antes de sua renovação e difusão nacional e mundial nos anos 1990 (COSTA, 2008; SILVA, 2004).

O Maracatu Nação recifense, com base na narrativa de Koslinski (2011), parece se recriar e adquirir múltiplas faces a partir dos anos 1980, nos quais ressurgem algumas nações, como a Nação Elefante e Leão Coroado, com apoio de autoridades locais e do Movimento Negro Unificado. Em 1989, é criado o Maracatu Nação Pernambucano - que pratica o Maracatu de forma mais estilizada e "não racializada" - por jovens de classe média, o que ajudou a levar o Maracatu para outras classes sociais, estados e até ao exterior (METZ, 2008). Na década de 1990, essa disseminação é reforçada pelo sucesso, na indústria cultural, do movimento Mangue Beat, com destaque a Chico Science e Nação Zumbi (UCELLA; LIMA, 2013). Por um lado, novas nações de Maracatu eram criadas nos bairros populares de Recife, algumas alegando ser continuação de homônimos muito antigos (LIMA, 2014). Por outro, surgiam os grupos percussivos, ou "Maracatus estilizados", em bairros de classe média de Olinda e Recife, na senda do Maracatu Nação Pernambucano. Em 2001, foi criado o Carnaval Multicultural do Recife, quando o Maracatu passa a receber tratamento semelhante ao que outrora era dispensado ao frevo - que já disputava espaço com escolas de samba e axé (PINTO, 1996).

Ivaldo Lima (2014, p. 305) defende que o Maracatu Nação é manifestação da cultura negra, "identificada com práticas e costumes feitos de forma comunitária, que trazem consigo sentidos compartilhados por grupos", além de recorte racial. Já os grupos percussivos seriam "agremiações de jovens" que vêm de diferentes localidades, em sua maioria brancas e brancos de camadas médias, quase sempre apenas cultivando a música. Em sentido mais positivo, Laís Garcez (2013) trata o Maracatu como "performance afro-diaspórica”, conformando ao longo das últimas décadas uma grande rede de trocas entre nações e grupos, com a "multiplicação das formas de vive-lo" (GARCEZ, 2013, p. 21). 
Um dos poucos grupos percussivos tratados pela bibliografia é muito relevante para esse texto. É, justamente, o Arrasta Ilha, de Florianópolis, que teve entre seus fundadores o criador do grupo de Maracatu da universidade pesquisada, Tiago. O Arrasta Ilha, sintomaticamente, vai enfrentar dilemas que serão revividos na trajetória do grupo universitário: de início, a dissociação da música e dança em relação ao complexo corpus do Maracatu Nação; algum tempo depois, a atração pela tradição, "autenticidade" e religiosidade representadas pelo Maracatu nativo (PRAZERES, 2012).

Consideramos que para abordar o grupo percussivo de Maracatu na universidade, vale a pena fazer uso de uma categoria que se revelou valiosa em trabalho anterior, desenvolvido por nossa equipe de pesquisa: práticas culturais juvenis (GROPPO; GOUSSAIN, 2016). Na esteira da definição de práticas culturais por Roger Chartier (1995), a categoria destaca "os modos de usar" e "as práticas sociais", enfatizando os usos, a apropriação e a produção de sentidos dos elementos culturais populares disponíveis. A categoria práticas culturais juvenis trata de atividades no campo das artes, organizadas e realizadas por sujeitos jovens. A categoria, de um lado, se refere à identificação etária dos sujeitos que a praticam - jovens. De outro, qualifica práticas com um termo que também é nativo, cultura, que tem sido usada pelos jovens que pesquisamos para definir, especialmente, as atividades no campo da música e da dança.

Temos, de um lado, uma prática originalmente associada à cultura popular negra (HALL, 2003) praticada originalmente no Brasil, mais especificamente em Pernambuco - o Maracatu de Baque Virado. De outro, sujeitos jovens que não são, em sua maioria, oriundos das classes populares e grupos étnicos negros, mas sim, jovens da universidade, em um estado do Sudeste, mais caracteristicamente das classes médias baixas e, em sua maioria, brancas e brancos. Há, ainda, outro paradoxo que faz contrastar uma característica específica da percussão do Maracatu de Baque Virado tradicional e o grupo da universidade: em sua grande maioria, os membros do grupo são mulheres, algumas delas, ativistas em coletivos feministas 5 .

\section{O Maracatu na universidade}

Quando Tiago - um dos fundadores do grupo percussivo de Maracatu Arrasta Ilha em Florianópolis - se tornou professor da universidade mineira em 2004, iniciaria a história do

\footnotetext{
${ }^{5}$ A principal referência aqui para tratar de gênero, graças às relações que estabelece entre gênero e educação, é Guacira Lopes Louro (1999).
} 
grupo de Maracatu nessa universidade. Segundo Tiago, o Arrasta Ilha tinha organização bastante horizontal, sem liderança e "libertária", características que buscou implantar também no novo grupo:

\begin{abstract}
Tiago: Não havia grupo similar na região [...], então eu comecei já conversando com alguns estudantes, sobre a possibilidade de montarmos um baque, um grupo muito dentro da proposta que foi o Arrasta Ilha, que era uma proposta descentralizada, coletiva, política [...]. O Arrasta Ilha sempre estava envolvido com projeto social, com manifestações, mobilizações.
\end{abstract}

Sem recursos para comprar ou montar instrumentos, informalmente começaram treinando baques na carteira e fizeram oficinas de canto e dança. De modo similar ao Arrasta Ilha, buscavam "trabalhar os ritmos e elementos" via "proposta livre de criação", escrevendo loas, escolhendo cores, com base em muito diálogo e criatividade (Tiago). Um servidor da universidade, lotado na Extensão, sabendo de verba excedente, propôs ajudar o grupo e fez orçamento de alfaias artesanais - algumas até hoje usadas. "Quando os instrumentos chegaram, a galera já saiu batucando, porque a gente já estava cansado de bater na carteira.” (Tiago).

Tiago se afastou do grupo em 2012, para o seu doutoramento. Mas, segundo ele, “o grupo tomou pernas próprias, o grupo é independente, autônomo [...]. A questão burocrática era só ter um coordenador para o grupo". Desde então, a coordenação é exercida quase que apenas formalmente por docentes com boa proximidade com o grupo, ficando a condução do baque e dos ensaios a cargo das estudantes - pois, desde então, apenas mulheres estudantes exerceram a regência.

O grupo de Maracatu na universidade mineira conta com 15 integrantes mais efetivos - em alguns momentos, chegou a ter menos pessoas. Segundo Tiago, "o grupo sempre foi marcado por uma circulação muito grande de pessoas, típico do Maracatu de universidade", característica que tem permanecido.

As atividades habituais ocorrem no campus central da universidade, em espaço aberto, aos domingos, a partir do final da tarde, com três ou quatro horas de duração. Durante a observação, realizavam essas atividades em dois módulos: a oficina, para membros novos, e o ensaio do grupo para apresentações. Aprendem e ensaiam os instrumentos típicos do Maracatu: apito da regência, gongué, ganzá, agbê, caixa e alfaia. As oficinas também têm a intenção de atrair novos participantes, e costumam ter maior número de pessoas no início do ano - no início de 2016, chegaram a ter 60 participantes. Também há oficinas de manutenção dos instrumentos. 
Uma atividade exercida desde a origem do grupo é a participação em atividades culturais do município. Mais recentemente, têm se destacado os Encontros de Matrizes Africanas. Eles costumam ser realizados aos domingos, cerca de quatro vezes por ano, na praça do terminal de ônibus urbano, envolvendo práticas culturais como folia de reis, samba de roda, samba de coco, jongo, congada, afoxé e capoeira, assim como manifestações das religiões de terreiro (Candomblé e Umbanda): "Foi o primeiro evento que toquei quando entrei, e é um evento apaixonante, que faz o coração pulsar, é um evento ligado à religião" (Estela). Isso é reforçado por Pedrita: "O encontro de matrizes africanas para mim é o mais importante [...]. Com ele abrimos outras portas na cidade, como lá no bairro popular, um evento de terreiro com o pessoal do bairro, com jongo, que são seculares”.

Em especial a partir de 2016, o grupo passou a participar de festivais de Maracatu no Sudeste, em destaque o anual Encontro de Maracatu de Baque Virado de Piracicaba, no qual conheceram o mestre da nação pernambucana que apadrinhou o grupo. Há relatos de participantes que foram, individualmente, conhecer Recife e algumas das nações de Maracatu pernambucana, como Estela. Esses relatos narram uma jornada de aprofundamento no universo do Maracatu e até de autoconhecimento de grande relevância

Os relatos sobre a inserção no Maracatu trazem diversos elementos sobre a importância do grupo para a sociabilidade, e por meio da participação em uma atividade cultural e significativa, a permanência na Educação Superior. Para Estela, o Maracatu tornou a vida na universidade "bem mais suportável”, tal qual uma "válvula de escape". Ela também narra a importância do grupo para a criação de amizades e vínculos, assim como uma prática cultural plena de significado:

Estela: Meu ciclo social começou ali [...] E eu moro com elas [...]. Minha identidade se criou lá dentro. São com eles que dou rolê. [...] Eu abri mão de muita coisa, eu nunca liguei, eu nunca fui pirada na universidade, como 'nossa, eu preciso do meu diploma'. Sei que preciso me formar um dia, mas encontrei minha felicidade, vim em busca de minha felicidade e encontrei o Maracatu... Sem o Maracatu eu não vivo mais... Quando eu me formar, eu tenho que ir tocar em outro grupo.

O Maracatu tem sido fonte de rendas para Pedrita, que recebe bolsas ensinando Maracatu em projetos sociais, bem como tem sido uma forma de ela se inserir na própria vida cultural do município, para além da universidade:

Pedrita: Eu vivo de música, graças ao Maracatu. Na minha vida é algo fundamental, que não vou deixar de fazer, não consigo abrir mão nem do cursinho popular, nem do Maracatu. Na minha inserção no município, as pessoas me conhecem por causa 
do Maracatu, as pessoas do terreiro [...]. Maracatu é algo que vou levar para minha vida, tenho tatuado o símbolo do grupo em mim e carrego o colarzinho com o símbolo.

Nas entrevistas de Israel e Juliana, todos esses elementos reaparecem: o Maracatu como fonte de significações para a vida na universidade, importante meio que as e os estudantes criam para a permanência na Educação Superior e o grupo como lugar de sociabilidades e formação de amizades e, enfim, como inserção da e do jovem na vida cultural do município:

Israel: O maraca foi pra mim aquela coisa de fazer algo além da sala de aula. Para mim, a aula costuma ser cansativa [...]. Acho que para muita gente é uma válvula de escape da questão acadêmica [...] e traz para a universidade uma cultura muito rica, que é o Maracatu. Acho que eu perderia muito se não tivesse esse grupo aqui na universidade, pois aqui é local elitizado. O Maracatu aparece como maneira de resistência de cultura popular na universidade [...]. Apaixonei-me desde o início [...]. Quando eu estou tocando, o maraca me faz esquecer todos os problemas [...] O Maracatu me proporcionou muitas amizades boas [...] gosto de todo mundo. Às vezes, está todo mundo saturado da faculdade, vamos num barzinho, trocamos uma ideia, rimos, brincamos no baque [...] para enfrentarmos a semana toda na universidade.

Juliana: Sem o Maracatu, acho que eu não teria nem terminado o curso [...]. Acho que não teria dado conta da carga emocional e psicológica, não teria dado conta de terminar aqui. [...] Maracatu é família, como mestre Igor fala [...] é aquela família que a gente escolhe [...]. Estamos sempre conversando e trocando ideia, estamos presentes graças às tecnologias. [...] Foi a partir do Maracatu que eu fui para o terreiro, que fui para o projeto social, que estava dentro da escola estadual, e eu levei a cultura marginalizada negra para dentro da escola de periferia, levei Maracatu e foi lindo, com o movimento negro, com a prefeitura, nos festivais [...]. Quem eu seria se não fosse o Maracatu? Eu não tenho ideia, porque eu conheci muitas pessoas e muitos lugares por meio do Maracatu, muitas realidades [...]. Maracatu é a minha vida. Meu filho e o Maracatu é minha vida, eu quero morrer vivendo Maracatu.

O relato de Juliana é marcante ao comparar o grupo a uma família. A imagem do coletivo estudantil autogerido como "família" é recorrente nos relatos dos membros dos grupos investigados pela pesquisa, seja o cursinho popular, o grupo evangélico e, até mesmo, como metáfora da união das e dos estudantes durante a ocupação estudantil. Assim como Juliana, diversos relatos sobre estes coletivos também falam da família que se escolhe ou se cria, depois de ter que deixar a família original, que ficou longe.

Apesar da relevância do grupo de Maracatu para a permanência da discência na universidade, e para levar o próprio nome da universidade em ações culturais que repercutem no município, há registros no presente, mas principalmente no passado, de tensões entre o coletivo e a comunidade universitária. Tiago, criador do grupo, relata o preconceito explícito ou latente em relação à cultura popular negra, dados os seus vínculos diretos e indiretos com as religiões de terreiro, bem como o principal foco das reclamações de discentes e docentes: o 
barulho dos tambores. Devido ao barulho dos tambores, as oficinas acontecem aos domingos, quando não há outras atividades acadêmicas na universidade. Também, às vezes, o grupo ensaia em um horário em que são permitidas manifestações culturais com som mais alto: entre às $17 \mathrm{~h}$ e às $19 \mathrm{~h}$.

A transformação do grupo em projeto de extensão, logo em seus primeiros anos, deu mais legitimidade ao Maracatu na universidade, com a qual, apesar disso, ainda mantém uma relação ambígua. A intensiva e exigente vida acadêmica dificulta que mais discentes e docentes se envolvam com o Maracatu, mesmo que seja para ouvir seus ensaios e apresentações:

P.: Tem muita gente que gosta, mas tem uma parcela conservadora da universidade que não gosta, tanto que a gente não podia ensaiar dentro da universidade na hora do almoço. Os professores reclamavam, os estudantes reclamavam, ligavam para a polícia quando íamos tocar em outros lugares, mas passamos a reivindicar esse lugar como nosso e agora, às quatro ou cinco horas, tocamos aqui, somos um projeto de extensão. Mas as pessoas que apoiam o movimento sempre estão aqui nos vendo ensaiar. Muita gente sai do almoço e fica assistindo.

I.: É um dos grupos e projetos de extensão mais antigos que a universidade tem. Mesmo com o preconceito de professores e alunos, nos mantemos vivos como um movimento cultural e político. [...] Tem uma galera que gosta bastante, cantam, dançam, têm vontade de participar, mas têm vergonha ou acham que não vão conseguir pegar o baque, como eu também achei [...]. Mas tem uma galera que curte e defende o nosso trabalho. Mas tem uma galera que carrega um preconceito, da questão de achar que é macumba ou que faz barulho dentro da universidade. Há vários estereótipos em relação ao Maracatu, como achar que todo batuqueiro é da área das Humanas, que faz três matérias. Tem uma galera que ofende a gente. Mas dentro da universidade somos um grupo de resistência.

A pró-reitoria de extensão tem dotado o grupo de Maracatu com uma bolsa de extensão, além de algum apoio para a compra de instrumentos e materiais, bem como auxílio para a participação em festivais e encontros de Maracatu. Entretanto, os membros do Maracatu se queixam de que outros projetos ligados às artes ditas "eruditas" têm recebido maior apoio da pró-reitoria de extensão, como a camerata e o coral: "Camerata, cultura clássica, de sociedade elitizada, encontra muitas vezes mais portas abertas e mais bolsistas de extensão" (Juliana).

O principal momento de tensão entre o grupo de Maracatu e a pró-reitoria de extensão se deu durante a pesquisa de campo, no final de 2017, quando fortes chuvas causaram infiltração que molhou os instrumentos guardados na sala do prédio de extensão e danificou materiais que seriam usados para fabricar novos instrumentos. O grupo publicou nota com forte crítica à pró-reitoria nas redes sociais, relatando que o problema já tinha acontecido em 2016, mas não foi resolvido, e que a pró-reitoria se negou a ceder outro espaço para o grupo 
guardar seus materiais. A nota reconhecia que a extensão apoiava o grupo com uma bolsa e alguns recursos, mas estes eram insuficientes e menores do que se destinava a projetos ligados às artes ditas "eruditas".

Apesar do conflito, não houve ruptura, e o grupo continuou como projeto de extensão em 2018, mas buscando alternativas de financiamento, bem como maior aproximação com projetos sociais e culturais, planejando uma futura autonomia financeira.

A principal articulação do grupo, desde suas origens, dentro da universidade, tem sido o chamado movimento estudantil. Desde pelo menos as greves estudantis e ocupações da universidade em 2012 e 2013, o baque do Maracatu é usado como forma de agitação, para chamar estudantes às assembleias e até para interromper momentaneamente as aulas. Isso se repetiu no movimento de 2016.

E.: Por mais que a gente cante loas e tenha um teor religioso e não seja tão político, o pessoal está sempre chamando a gente [...]. Acredito que eles entendem que o Maracatu é um grupo de resistência e também porque o grupo está aqui há muito tempo, tem quase 14 anos.

I.: Acho que esperam algo da gente séria na questão cultural [...]. A questão política também, quando tem movimento, sempre nos chamam. [...] A gente não é perfeito, erramos em grande coisa. Teve um evento que me senti meio frustrado, quando estava tendo movimentações de greve. Fomos aos corredores, atrapalhando as aulas. Poderíamos ter feito outro tipo de intervenção cultural, exemplo, um baque no hall. Senti que não deveríamos ter feito aqui, pois potencializamos os estereótipos da galera.

Estela e Israel consideram o Maracatu como um projeto, sobretudo, cultural, incluindo fortes elementos religiosos. Entretanto, pela antiguidade do grupo e pelo respeito que adquiriu diante das entidades estudantis, tem sido chamado para dar apoio na mobilização para as ações coletivas. Israel, entretanto, se incomodou com a interrupção forçada das aulas, durante a greve estudantil de 2016 - atitude, como discutimos em artigo sobre a ocupação (GROPPO et al., 2017), que sofreu uma autocrítica do próprio movimento que, a partir daí, passou a ter uma atitude de diálogo, ao invés do confronto, com quem não queria interromper as atividades acadêmicas durante a greve.

Durante 2016, o grupo de Maracatu participou de outras atividades políticas, promovidas com o apoio do movimento estudantil, que foram para além dos portões da universidade. Em março, participaram do evento Não me dê flores, lute comigo - a Primavera continua, na praça do terminal de ônibus urbano. Tratava-se de parte de um conjunto de ações em todo o país - a Primavera feminista - que tinha como pauta principal a derrubada de um sinistro projeto de lei, patrocinado por Eduardo Cunha, então presidente da Câmara dos 
Deputados, que dificultaria o aborto para mulheres engravidadas por estupro. Em abril de 2016, o Maracatu participou de ato de desagravo, junto a diversos outros coletivos da universidade, com apoio da direção da Faculdade de Ciências Humanas, no Núcleo de Consciência Negra, pichado com frase racista.

Como dito, o Maracatu foi chamado para apoiar a greve estudantil e a ocupação da universidade em outubro de 2016. O desgaste físico e psicológico da longa ocupação, que terminou derrotada em suas principais pautas - contra a Reforma do Ensino Médio e a Proposta de Emenda Constitucional 241/55 -, implodiu o principal coletivo estudantil político atuante no movimento, justamente o que dirigia o DCE, e enfraqueceu os demais coletivos políticos. Contudo, os relatos são diferentes em relação ao Maracatu, que teria se unido mais durante a ocupação. No retorno do ano letivo de 2017, enquanto os coletivos de caráter político se esvaziavam, o Maracatu se fortaleceu - indicando que, dificultado o caminho da política, a participação social de jovens buscou mais o caminho das práticas culturais.

\section{Tensões, tradição e religiosidade}

Apesar da grande importância do Maracatu para a permanência, a socialização e a sociabilidade das e dos discentes que integram o grupo, a vida em um coletivo estudantil dificilmente é isenta de tensões. Algumas delas foram observadas durante a pesquisa de campo e, principalmente, relatadas nas entrevistas.

Nas entrevistas, os membros buscaram afirmar que, na atualidade, as tensões e os conflitos de caráter interno tinham sido superados. Entretanto, em diversos momentos se percebem, ao menos, tensões latentes, no que se refere às relações do grupo com a tradição, a religiosidade, à nação que se filiaram e ao mercado cultural, algo que as observações, em parte, corroboram, como buscaremos demonstrar nessa seção. Tal demonstração é importante para este texto, já que busca captar a realidade dinâmica das organizações juvenis, bem como suas complexas relações com o contexto social que as envolvem, não apenas no âmbito da universidade, mas no conjunto das relações econômicas e políticas mais gerais.

Primeiro, o grupo busca se equilibrar entre fontes organizativas mais próximas da autogestão e horizontalidade, e fontes que valorizam a centralização e a verticalidade. Este tenso equilíbrio tem aparecido em todos os coletivos juvenis investigados, cada qual com suas especificidades, a depender da instituição com a qual estão ligados ou têm fortes relações (partido, movimento social, organização religiosa e a própria universidade). No caso do grupo de Maracatu, ainda que tenha havido atritos com a pró-reitoria de extensão, a principal referência externa ao grupo estudantil tem sido menos uma instituição tendencialmente 
centralizadora, e mais um conjunto de valores e práticas exógenos que são tomados como referência: as tradições do Maracatu Nação pernambucano.

Para além das tensões na forma de conduzir e organizar o grupo, as tradições do Maracatu Nação têm obrigado o grupo, a todo o momento, a se redefinir ou se posicionar diante das fontes pernambucanas. Algumas passagens das entrevistas comunicam que essa relação complexa, por vezes angustiada, com as fontes do Maracatu Nação, em especial com as noções de autenticidade e religiosidade, é recorrente na história do grupo. Outrora, mestres de diferentes nações já tinham feito oficinas com o grupo percussivo da universidade, mas os registros e o acúmulo dessas discussões se perderam, em especial, graças à grande rotatividade dos seus membros. Isso tem obrigado o Maracatu da universidade, de tempos em tempos, a ter de enfrentar e tomar posição frente aos dilemas recorrentes que se colocam diante dele.

O dilema mais patente, e que parece ter sido mais bem resolvido, é o fato do Maracatu Nação pernambucano ser predominantemente, em especial no que se refere à percussão, um domínio masculino, enquanto o grupo da universidade é quase todo formado por mulheres - e a própria regência, desde a saída de Tiago, tem sido exercida por mulheres.

P.: Na questão de gênero, no grupo tem mais mulheres que homens. Isso é interessante, porque dentro do Maracatu, por tradição, sempre foi tocado por homens. [...] Acho que por serem mulheres as regentes, também, desde que entraram regentes mulheres, nenhum homem quis se impor sobre uma menina. Acho que os meninos que estão no Maracatu entendem bem isso e respeitam, eles não nos silenciam. [...] Aqui no grupo, houve um momento em que só havia mulheres, não foi algo proposital, acabou acontecendo.

Algumas integrantes do grupo de Maracatu fizeram Trabalhos de Conclusão de Curso (TCC's) e Iniciações Científicas (IC's) - inclusive a coautora deste artigo - com base no Maracatu. Entretanto, excetuando o caso desta coautora, os demais trabalhos trataram das nações de Pernambuco em vez do grupo da universidade, em mais uma busca por resolver os dilemas que atravessam suas práticas culturais juvenis, um acerto de contas com as fontes do Maracatu.

Outro dilema pouco problematizado foi o racial, já que as e os integrantes, em uma pequena maioria quando da realização da observação, não eram negras e negros. Esse cultivo do Maracatu de Baque Virado por populações brancas, de classe média, juvenis e fora de Pernambuco é justificado por Estela, em consonância até com a posição do mestre Igor, como uma forma de preservação dessa tradição. Estela narra que o Maracatu era "uma cultura que estava morrendo no Nordeste, mas que depois passou por um momento de ascensão e acabou 
se expandindo para fora do Nordeste". Segundo ela, essa expansão "salvou o Maracatu” e, "por mais que a gente seja bem diferente do Maracatu tradicional [...], a gente faz parte da resistência desse Maracatu".

Nos relatos, o principal foco de tensões, nessa busca de conciliar as práticas culturais juvenis e as tradições do Maracatu Nação pernambucano, foi a religiosidade. Para Garcez (2013), a relação da nação com o universo religioso dos terreiros de Xangô (semelhante ao Candomblé da Bahia) ou Jurema (semelhante à Umbanda) é importante critério de legitimação da "autenticidade" das nações do Maracatu. Segundo Koslinski (2011, p. 8), "onde a manifestação se tornou, dentre outras coisas, atração turística, percebemos que categorias como religiosidade, tradição e mesmo africanidade se tornaram valores presentes nos grupos, valores que, de certa forma, lhes conferem autenticidade". Cada nação articula de modo próprio essas categorias, por exemplo, na nação Porto Rico, estudada por Koslinski (2011), a religiosidade é muito marcante.

Veja-se que o próprio Arrasta Ilha, outro grupo percussivo juvenil do qual Tiago participou da criação, enfrentou esse dilema, levando integrantes a estudarem religiões de terreiro cujos elementos apareciam no Maracatu - mas sem levar tais elementos religiosos para apresentações e oficinas ao público externo. Algo semelhante acontece no Maracatu da universidade, e as entrevistas nos levam a concluir que se trata de um dilema recorrente.

E.: A gente não está envolvida diretamente com a religião, pois o grupo é muito amplo, tem pessoas de diversas religiões, tem pessoas sem religião. Mas, sinceramente, o Maracatu depende da religião, o fundamento dele é religioso. A gente tem que respeitar. É uma coisa que temos que aperfeiçoar, a gente ainda não conseguiu atingir esse ideal, de conseguir estudar a religião e entender um pouco sobre ela sem ser da religião. [...] A parceria que temos com o terreiro para mim é uma das coisas mais importantes.

Para as três integrantes do grupo entrevistadas, o Maracatu propiciou aprendizados muito importantes referentes à religião e à espiritualidade. Esse aspecto só não foi relevante na entrevista com Israel. Mas, em relação às estudantes, o Maracatu e os estudos sobre as religiões de terreiro propiciaram um autodesenvolvimento dos aspectos espirituais, segundo elas. Mas, paradoxalmente, isso não significou a filiação religiosa - ainda que Juliana tenha frequentado o terreiro de Candomblé da cidade.

P.: Eu cresci dentro das igrejas evangélicas e eu sempre tive muito medo e preconceito com as religiões de matrizes africanas e com o Maracatu a gente tem parceria com o terreiro, com várias manifestações de culturas africanas, com a Umbanda, o Candomblé, e eu me aproximei muito e desconstruí muitos conceitos que eu tinha antes de entrar na universidade, antes de eu entrar no Maracatu. Eu vejo 
que eu não tenho uma religião, não sou da Umbanda, não sou do Candomblé, não sou cristã, mas eu respeito muito dentro do Maracatu a religião. É muito importante para mim desde a questão de respeitar um instrumento, saber que eu estou levando uma história quando eu toco um tambor e que essa história está ligada à questão dos escravos. [...] Mas dentro do Maracatu a gente não exige que tenha que ter uma religião, porque aqui a gente só tem a parte percussiva, não nasceu dentro de um terreiro, não é como lá em Recife. [...] A gente sabe que tem a ligação com a religião de matrizes africanas, mas cada um é livre para ter sua religião.

Para Pedrita, essa crescente preocupação do grupo com a religiosidade foi coroada com a filiação a um Maracatu Nação de Recife, quando o mestre Igor passou a orientar o coletivo a respeito dos elementos religiosos do Maracatu. O relato de Pedrita ilustra a solução criada pelo grupo, orientada pelo mestre Igor que, com base no relato de Juliana, recuperou uma prática anterior do Maracatu da universidade: o conhecimento mais profundo dos elementos religiosos e a ligação mais estreita de alguns membros do grupo com a religião de terreiro, como forma de prover orientação e proteção espiritual.

P.: A gente começou a ter mais cuidado com essa questão depois que a gente começou a fazer parte da nação e o mestre começou a falar sobre isso com a gente, porque nas loas do Maracatu têm muito os orixás nas letras, são trazidos muitos elementos da religião que a gente não entendida. [...] Veio o mestre aqui nesse ano e a gente começou a ter mais cuidado. [...] A gente se reúne depois do baque e conversa sobre algumas questões. Algumas pessoas vão ao terreiro.

A filiação do grupo à Nação de Recife e o apadrinhamento pelo mestre Igor são um novo e crucial capítulo nesse empenho de conquistar a legitimidade do grupo perante as "tradições" do Maracatu Nação. Provavelmente, o gesto mais forte em direção à almejada "autenticidade" do grupo percussivo, foi um autorreconhecimento - e o reconhecimento perante outros grupos, em seus constantes périplos em eventos e festivais no Sudeste - como coletivo que pratica com legitimidade e qualidade a musicalidade do Maracatu, inclusive porque pesquisa as relações destes elementos musicais com outros elementos fundamentais do Maracatu Nação, como a religiosidade, a ancestralidade, a festividade, a dança, a resistência, entre outros.

Mestre Igor é batuqueiro de um dos muitos Maracatus Nação nascidos ou recriados na grande onda de revigoramento do Maracatu pernambucano nos anos 1990. Sua nação pertence à linhagem Angola - enquanto a maioria das nações é Nagô -, caracterizada principalmente por um ritmo mais ligeiro no baque. Segundo Estela, o apadrinhamento é importante tanto para o grupo da universidade, para sua legitimação, quanto para os mestres e as nações, não apenas para a valorização dessas práticas culturais, mas também como fonte de recursos econômicos: 
E.: O Mestre Igor apadrinhou a gente com a mesma boa vontade, porque ele sabe que é uma maneira de manter a nação dele viva de alguma maneira fora do Recife. Ele passa por várias dificuldades, lá também tem as mesmas que passamos aqui para manter o grupo, ainda mais sendo nação. É uma forma de manter o legado deles para fora, e assim os dois ganham, o grupo se consolida mais e a nação se mantém viva.

Em contrapartida, também parece haver uma história das relações do grupo universitário de Maracatu com os projetos culturais e o setor local de shows. Tiago dá indícios em sua entrevista, quando conta da participação do Maracatu em diversos eventos e festas universitárias, considerando, inclusive, que o Maracatu outrora tinha uma grande ligação com a vida cultural do município - algo que a participação nos Encontros de Matrizes Africanas parece estar recriando.

Nas entrevistas, há alguns relatos de experiências com o Maracatu em projetos culturais no município sede da universidade e em outros municípios. Em 2018, o grupo iniciou suas atividades já com a projeção de depender menos da extensão e da própria universidade. Tem a intenção de conseguir recursos próprios para comprar seus instrumentos - e as oficinas cobradas com mestre Igor são uma destas formas. Têm aberto shows de artistas midiáticos em apresentações no município.

Os desdobramentos das atividades do grupo, em 2017 e 2018, demonstram o quanto as práticas culturais juvenis são dinâmicas, intensamente criativas e estão em constante transformação. A aproximação com uma nação de Maracatu, na busca por legitimidade e resolução dos dilemas do grupo, fez com que fosse necessário procurar também outras formas de renda, enquanto aprofundaram a inserção nos projetos culturais e espetáculos do município.

\section{Autoformação e coformação}

Tão dinâmica e rica quanto o tenso diálogo entre praticantes culturais, tradições e recriações, tem sido a formação cultural e política ensejada pela participação no Maracatu da universidade. Tanto quanto os demais coletivos estudantis pesquisados, tem sido largamente uma autoformação cultural e política, mas que não prescinde do diálogo com pessoas adultas que são peritas no que é o tema aglutinador do coletivo - como, nesse caso, o apadrinhamento por um mestre do Maracatu Nação pernambucano.

A adaptação às rotinas da vida acadêmica tem sido relatada, em entrevistas de todos os coletivos, como uma grande dificuldade das e dos jovens estudantes da universidade. Os relatos do Maracatu trazem diversos elementos acerca desta adaptação e da relação entre a 
universidade e o grupo percussivo. Como vimos na segunda seção deste trabalho, a prática do Maracatu foi fundamental para a inserção destas e destes jovens na própria universidade e para sua permanência. Contudo, também há tensões e descontinuidades, quando as exigências acadêmicas colidem com as necessidades do Maracatu:

E.: Eu abro mão da minha graduação para ir fazer oficina, ir a eventos. Altas faltas. [...] Se eu abro mão, eu piro na universidade. É um lugar em que eu me encontrei mais do que a minha graduação... Eu amo geografia, mas o Maracatu me faz mais feliz. [...] Minha dedicação integral custou alguma coisa. [...] Talvez um pouco mais de compreensão vinda de alguns docentes não fosse custar o tanto que custou para mim. [...] Talvez o meu posto de regente seja por isso, por eu ter me dedicado integralmente ao Maracatu.

Em um segundo momento, entretanto, o Maracatu volta a ser elemento integrador da e do estudante com o saber acadêmico, quando integrantes do grupo fazem trabalhos para as disciplinas, IC's e até mesmo o TCC com base no Maracatu Nação pernambucano, em mais um esforço para dar legitimidade ao grupo, estabelecendo relações entre a tradição e as práticas culturais juvenis, por meio de estudos sobre os elementos da cultura popular "original":

J.: Eu precisava trazer para a minha pesquisa algo que me movesse, que fizesse sentido para mim. [...] porque eu não teria terminado o curso, porque talvez eu não tivesse encontrado algo na academia algo com um significado tão forte para mim, e o Maracatu foi isso. Eu tinha várias crises na academia, eu não via sentido. Hoje, ao contrário, eu vejo que ela tem uma função genial se você souber aproveitar. [...] Ficou lindo, ali eu entendi a atuação como acadêmica da pesquisa popular e isso me ajudou a continuar na academia, mesmo com todas as crises que a gente passa. Foi assim casar um grande amor com esse mundo acadêmico e de saber o impacto que meu trabalho tem para a nação.

Há outro lado: a universidade, por meio do seu saber acadêmico legitimado, pode dar um acréscimo de reconhecimento a uma nação, ainda mais sendo ela vista como "nova": "O dia em que entreguei, imprimi meu TCC e entreguei na mão do mestre Igor, ele chorou. Mestre Igor comentou muito em Recife com sua comunidade que aquilo seria muito importante para o reconhecimento da nação dele" (Juliana).

A rigor, entretanto, inclusive nas entrevistas, a vida acadêmica na graduação é associada, sobretudo, ao ensino. Os relatos sobre a contribuição do Maracatu para diversos aspectos da formação dos sujeitos, poderíamos dizer, para uma formação integral, indicam o quanto a participação nesse coletivo cultural é importante para além dos saberes acadêmicos. Os trechos citados abaixo comprovam isso. Israel ainda acrescenta outro elemento importante: a contribuição para sua formação como professor: 
I.: O maraca foi pra mim aquela coisa de fazer algo além da sala de aula. Para mim, a aula costuma ser cansativa. [...] Acho que para muita gente é uma válvula de escape da questão acadêmica [...] e traz para a universidade uma cultura muito rica, que é o Maracatu. Acho que eu perderia muito se não tivesse esse grupo aqui na universidade, pois aqui é local elitizado. O Maracatu aparece como maneira de resistência de cultura popular na universidade. [...] Acho que a universidade perderia muito se o Maracatu deixasse de existir. [...] Através das discussões que nós temos no grupo e também com o mestre Igor, mudei minha visão da universidade. A teoria que ele deu para gente aqui me desconstruiu muita coisa que peguei dentro da universidade. [...] O Maracatu me fez o Israel que sou hoje, tem coisas que aprendi mais no maraca que dentro da sala de aula. Acho importante por isso o maraca, outro meio de conhecimento além da sala de aula, principalmente na minha formação como professor.

E.: Quando eu entrei e vi a Juliana, eu falei, que menina maravilhosa, quero ser como ela. Mas não pensei em ser regente e ela era regente. [...] Eu era uma menina tímida. [...] Eu era totalmente insegura sobre mim, mas tive um pouco de persistência. [...] A primeira vez que eu cantei a resposta no microfone, lá em Nova Iguaçu, foi outra desconstrução. [...] Falei comigo mesma: "Olha o que está acontecendo com sua vida, você está tocando num auditório com um monte de gente."

Desde a saída do fundador do grupo, o docente Tiago, o Maracatu da universidade se caracterizou ainda mais como uma experiência de autoformação estudantil:

J.: O grupo é singular, ele é fenomenal, o seu funcionamento é praticamente autogerido por estudantes, e o que se espera dos estudantes é o oposto, que estudante não quer nada com nada, que a galera do tambor não quer nada com nada.

Além da autoformação, em oficinas na própria universidade, o grupo participa de processos coformativos, junto a outros grupos e mestres do Maracatu, em encontros nacionais de Maracatu, que são relativamente prósperos no Sudeste. Destaca-se a participação no encontro anual em Piracicaba, onde conheceram o mestre Igor.

Há, entretanto, uma dimensão mais pessoal desta autoformação, quando integrantes decidem viajar a Recife para um contato "direto" com a fonte das práticas que cultivam. Em Recife, a ou o viajante contata as nações, assiste a ensaios e participa de oficinas. Juliana aponta que, apesar de sua grande imersão no Maracatu, faltou a ela essa viagem. Quanto à Estela, apesar de seu pouco tempo no grupo, parece ter pesado, para a sua escolha como nova regente, o fato de ela ter feito essa imersão na terra onde nasceu o Maracatu de Baque Virado. Mas o seu relato destaca muito mais a transformação pessoal que a viagem suscitou, a ponto de quase abandonar sua graduação:

E.: Lá em Recife, tudo o que tinha na cabeça de Maracatu eu desconstruí. Parece que é um mundo diferente, um mundo de Maracatu que eu nunca imaginei como 
seria. [...] É um choque. [...] Eu voltei num estado de euforia, eu queria abandonar a faculdade e viver de Maracatu, fiquei eufórica.

Como dito na seção anterior, o grupo parece ter iniciado uma nova fase de sua história quando decidiu se filiar a uma nação do Maracatu pernambucano. Para além da troca de saberes interna ao grupo, Mestre Igor passou a desenvolver o que ele chama de "vivências" com o grupo, um processo formativo em que o sujeito considerado como detentor da tradição cultural original, um mestre do Maracatu, homem do povo, negro, adulto e pernambucano, vem trazer seus saberes para jovens integrantes de um grupo percussivo da universidade do interior de Minas Gerais.

Foi feita a observação da primeira vivência ministrada pelo Mestre Igor, em um fim de semana no campus mais afastado da universidade. A vivência começou com uma fala em tom coloquial, calma e terna, do mestre Igor, tratando sobre a relação com o instrumento, religiosidade, o canto, a diferença entre nação e grupo, a presença da mulher na regência, a diferença entre mestre e regente, bem como dicas práticas, loas, racismo e resistência popular. Dois pontos se destacaram como possível resolução aos principais dilemas do Maracatu universitário: a relação com a religiosidade e a legitimidade dos grupos diante das nações. $\mathrm{O}$ mestre explicou que os instrumentos representam orixás, que é preciso conhecer e respeitar essas relações, mas que isso não implica em adotar dada religião. Também, que a "vulgarização" do Maracatu, com a criação de muitos grupos, não necessariamente faz o Maracatu perder sua "essência", desde que os grupos respeitem as nações.

Em seus relatos, os membros do grupo reconhecem as contribuições do mestre para resolver seus dilemas e para aperfeiçoar sua musicalidade - ainda que o relato de Israel relembre que a nação a qual se filiaram é relativamente nova, portanto, sem a mesma capacidade de dar legitimidade aos grupos que adota, em comparação com nações consideradas mais antigas:

I.: A filiação foi algo bom, porque a gente não tinha uma referência como baque. Descobrimos que não sabíamos nem tocar caixa... Tínhamos uma referência e identidade como grupo, e filhos da Nação nos deixou essa identidade mais concreta. [...] O mestre é sensacional, é uma nação nova, mas sensacional... Ele é um paizão.

Há, enfim, outro lado do pêndulo, que é a atração pelo mercado cultural - seja a indústria de espetáculos, sejam os projetos culturais ligados a governos locais e organizações não governamentais. Essa atração se dá tanto por causa da vontade do grupo em ter maior autonomia em relação à extensão universitária, quanto como alternativa de sobrevivência 
financeira dos seus membros. Ainda que não apareça com destaque nas entrevistas, indícios apontam que essa atração é tão cíclica quanto a busca da legitimação diante do Maracatu Nação e, ainda, que tendem a ocorrer com certa simultaneidade. Há, assim, outra dimensão do coaprendizado, cujo envolvimento também é cíclico, tanto quanto a interlocução com mestres percussionistas: a relação com o mercado cultural e seus agentes - organizações sociais, poder público e pessoas intermediárias da indústria de entretenimento.

Os processos de coformação alargam os horizontes do grupo - para além da universidade - e os próprios limites da autoformação do Maracatu. Isso não significa que a autoformação tenha importância menor, pois ela parece estar a serviço, em especial, da construção das subjetividades das e dos praticantes do Maracatu, ou seja, conformam processos de subjetivação. Com base em François Dubet (2010), Maria Carla Corrochano (2008, p. 28) afirma que, "na lógica da subjetivação, o indivíduo busca confrontar-se de maneira crítica e autônoma com a sociedade, percebida como um sistema de produção e dominação". Os estudos de Juarez Dayrell (2002) sobre jovens das classes populares no Brasil têm mostrado como têm sido importantes as práticas culturais para que elas e eles possam construir relações expressivas, que configuram processos de subjetivação.

Já a coformação coloca esses sujeitos e o próprio grupo, por um lado, em contato mais próximo e profundo com o universo do Maracatu Nação pernambucano e, por outro, em suas relações com o mercado cultural, ensina a extrair a sobrevivência material das e dos brincantes, e a construir a autonomia financeira do Maracatu. Desse modo, a coformação constitui outras duas dimensões da socialização, segundo Dubet (2010). Primeiro, a integração, ou seja, quando "os indivíduos buscam manter e reforçar seus laços de pertencimento no interior de uma sociedade (vista como um sistema de integração) ou, em poucas palavras, procuram se conformar à cultura do grupo" (CORROCHANO, 2008, p. 28). Segundo, a estratégia, quando "os indivíduos são movidos por interesses em uma sociedade lida como um mercado, escolhem caminhos e buscam ferramentas na perspectiva de atender seus interesses e necessidades, o que implica na racionalidade instrumental” (Ibid., p. 28).

O grupo de Maracatu configura uma criativa combinação entre, de um lado, processos de subjetivação e autoformação, que permitem a construção de uma identidade significativa no campo das artes e até da religiosidade e, de outro, processos de socialização, ações estratégicas e práticas coformativas, a partir das quais o grupo e seus membros constroem relações socioeconômicas e culturais relevantes com outras instituições para além da universidade - relações que tendem a esvair, conforme as e os brincantes vão se graduando e deixando a universidade, mas que podem ser recriadas em momento posterior, como já 
aconteceu. Enquanto a autoformação é uma constante, o incremento dos processos de coformação tem sido cíclico.

\section{Considerações finais}

No início deste texto, formulamos uma questão provocada tanto pelo contato empírico inicial com o Maracatu da universidade, quanto com a bibliografia específica. Ela perguntava sobre os significados da recriação do Maracatu de Baque Virado por um grupo percussivo universitário, tão distinto das nações pernambucanas tradicionais.

Um olhar apressado, conduzido por categorias em oposição binária, poderia logo concluir que estávamos diante de práticas de apropriação, simulação e espetacularização que levavam a um empobrecimento do Maracatu e à sua mercantilização. Realmente, as relações com o mercado cultural podem levar a essas práticas e resultados, ao menos em parte, como inúmeros trabalhos comprovam.

Contudo, mesmo quando houver processos de apropriação e mercantilização, dificilmente isso encera todas as dimensões socioculturais envolvidas. No caso do grupo universitário investigado, as relações com o mercado cultural, além de cíclicas, são incipientes e tratadas antes como táticas de sobrevivência e autonomia do coletivo do que como objetivo. Isso atesta que resta muito a ser conhecido, em especial quando nosso olhar incide sobre o cotidiano das práticas culturais juvenis. Isso é feito, atendendo ao objetivo geral da pesquisa, por meio da análise das práticas formativas - autoformativas e coformativas - e por meio da compreensão dos significados da experiência de ser brincante de Maracatu por quem integra o grupo universitário.

Para tanto, a noção de práticas culturais juvenis mostrou-se muito relevante, permitindo abordar os processos de subjetivação suscitados pela experiência do Maracatu universitário, em especial pelo modo como as tensões e os dilemas dessa experiência vão surgindo, conforme o grupo aprofunda seus conhecimentos sobre o Maracatu Nação, no que se refere às relações de gênero, à tradição e à religiosidade. A noção de práticas culturais juvenis contribui, ainda, para acompanhar o processo largamente autogestionário de organização do Maracatu da universidade, intimamente ligado aos processos de autoformação e subjetivação, quando seus integrantes buscam uma vivência do Maracatu de Baque Virado mais "autêntica", com maior profundidade e menores contradições em relação às nações de Pernambuco.

A autoformação permite a construção de uma subjetividade mais integrada e coesa, tanto pela relação com a arte do Maracatu quanto pelo conhecimento de sua religiosidade e, 
em diversos casos, por meio da ressignificação do saber acadêmico, quando o Maracatu é tematizado em trabalhos para as disciplinas, TCC's e IC's. Há, ainda, a ida a Recife, uma prática autoformativa que já aponta para outro processo de aprendizado, a coformação. É porque a viagem à terra natal do Maracatu objetiva o contato direto com nações e oficinas com seus mestres, ou seja, processos coformativos que aprofundam a autoformação e buscam resolver dilemas persistentes do coletivo (relações de gênero, religiosidade e autenticidade).

Assim, o próprio processo autogestionário e autoformativo suscita questões internas que levam o coletivo a desenvolver outros processos de vivência e aprendizado do Maracatu: a coformação com o mestre pernambucano. A formação com o mestre aumenta a legitimidade do grupo percussivo tanto em relação às nações de Pernambuco, quanto aos demais grupos com quem se encontram nos diversos eventos e festivais de Maracatu no Sudeste. Há, enfim, a aproximação com o mercado cultural, tanto a indústria de entretenimento, quanto os projetos culturais de organizações sociais e do poder público. As relações com o mercado cultural apontam para táticas de promoção da autonomia financeira e até institucional do coletivo, diante das tensões com a extensão e parte da comunidade universitária, tanto quanto o esboço de práticas de sobrevivência financeira de alguns de seus membros.

Mas a potência do grupo reside principalmente nos processos autogestionários e autoformativos. Promove-se a constituição de subjetividades capazes de romper com barreiras sociais e culturais e distanciamento crítico, por meio do cultivo de formas de gestão e de aprendizado não convencionais, capazes de integrar saberes populares e conhecimentos acadêmicos, de formar identidades individuais e coletivas e dotar a vida na universidade da e do brincante de mais sentido e prazer. Não à toa, o movimento estudantil tradicionalmente se alia ao Maracatu em suas táticas de agitação e mobilização, tal a potência política ensejada pela profundidade das práticas culturais das e dos brincantes.

Tambores e loas continuam a ressoar resistência nos pátios da universidade.

\section{Referências}

ANDRE, M. E. D. A. Etnografia da prática escolar. Campinas: Papirus, 2009.

CARVALHO, E. I. Diálogo de negros, monólogo de brancos: transformações e apropriações musicais no maracatu de baque virado. 2007, 145 f. Dissertação (Mestrado em Antropologia), Universidade Federal de Pernambuco, Recife, 2007. 
CORROCHANO, M. C. O trabalho e sua ausência: narrativas de jovens no Programa Bolsa Trabalho no município de São Paulo. 2008. 450 f. Tese (Doutorado em Educação) Universidade de São Paulo, São Paulo, 2008.

COSTA, G. B. A festa é de Maracatu: cultura e performance no Maracatu Cearense. 19802002. 2008. 196 f. Dissertação (Mestrado em História Social) - Universidade Federal do Ceará, Fortaleza, 2008.

CHARTIER, R. "Cultura popular”: revisitando um conceito historiográfico. Estudos Históricos, Rio de Janeiro, v. 8, n. 16, p. 179-192, 1995. Disponível em:

<http://bibliotecadigital.fgv.br/ojs/index.php/reh/article/viewArticle/2005>. Acesso em: 10 nov. 2018

DAYRELL, J. O rap e o funk na socialização da juventude. Educação e Pesquisa, São Paulo, v. 28, n. 1, p. 117-136, 2002. Disponível em: 〈www.scielo.br/pdf/ep/v28n1/11660.pdf>. Acesso em: 05 maio 2018.

DUBET, F. Las lógicas de acción. In: Sociología de la experiencia. Madri: CIS, Editoial Complutuense, 2010. p. 101-124.

PARK, M. B.; FERNANDES, R. S. (Orgs.). Palavras-chave em educação não formal. Holambra: Setembro, Campinas; CMU, 2007. p. 31-52.

GARCEZ, L. S. Os movimentos do Maracatu Estrela Brilhante de Recife: os "trabalhos de uma "nação diferente". 2013. 158 f. Dissertação (Mestrado em Antropologia) - Universidade Federal Fluminense, Niterói, 2013.

GARCIA, V. A. Educação não-formal: um mosaico. In: PARK, M. B.; FERNANDES, R. S. (Orgs.). Palavras-chave em educação não formal. Holambra: Setembro, Campinas; CMU, 2007. p. 31-52.

GROPPO, L. A. et al. Ocupações no Sul de Minas: autogestão, formação política e diálogo intergeracional. ETD- Educação Temática Digital. Campinas/SP v.19 n.1 p. 141-164, 2017. Disponível em: <https://periodicos.sbu.unicamp.br/ojs/index.php/etd/article/view/8647616>. Acesso em 10 abr. 2019.

GROPPO, L. A.; GOUSSAIN, E. Dimensões educativas não formais e informais das práticas culturais juvenis na cidade. Inter-Ação, Goiânia, v. 41, n. 2, p. 265-286, maio/ago. 2016. Acesso em 10 abr. 2019.

HALL, S. Notas sobre a desconstrução do popular. In: Da diáspora: Identidade e Mediações Culturais. Belo Horizonte: Editora da UFMG, 2003, p. 247-264.

KOSLINSKI, A. B. Z. "A minha nação é nagô, a vocês eu vou apresentar”: mito, simbolismo e identidade na Nação do Maracatu Porto Rico. 2011. 153 f. Dissertação (Mestrado em Antropologia) - Universidade Federal de Pernambuco, Recife, 2011. 
LIMA, I. M. F. Maracatu nação e grupos percussivos: diferenças, conceitos e histórias. História: Questões \& Debates, Curitiba, n. 61, p. 303-328, jul./dez. 2014. Disponível em: $<$ https://revistas.ufpr.br/historia/article/view/39020>. Acesso em: 10 maio 2018.

LOURO, G. L. Gênero, Sexualidade e educação: uma perspectiva pós-estruturalista. 3. ed. Petrópolis: Vozes, 1999.

MAGNANI, J. G. C. Etnografia como prática e experiência. Horizontes Antropológicos, Porto Alegre, ano 15, n. 32, p. 129-156, 2009. Disponível em: <www.scielo.br/pdf/ha/v15n32/v15n32a06.pdf >. Acesso em: 10 jun. 2017.

MEDEIROS, R. B. de. Maracatu Rural: luta de classes ou espetáculo? (Um estudo das expressões de resistência, luta e passivização das classes subalternas). 2003. 332 f. Tese (Doutorado em Serviço Social) - Universidade Federal de Pernambuco, Recife, 2003.

METZ, J. D. Cultural Geographies of Afro-Brazilian Symbolic Practices: Tradition and change in Maracatu de Nação. Latin American Music Review, Austin, v. 29, n. 1, p. 64-95, 2008. Disponível em: <https://www.utexaspressjournals.org/doi/abs/10.7560/LAMR38205>. Acesso em: 05 jul. 2018.

OLIVEIRA, R. C. O Trabalho do Antropólogo. 2. ed. Brasília: Editora Paralelo 15; São Paulo: Editora Unesp, 2006.

OLIVEIRA, S. A. de. Cultura popular e o Maracatu Rural: trilhando os caminhos do espetáculo. Cultur - Revista de Cultura e Turismo, ano 5, n. 1/especial, p. 58-70, 2011. Disponível em: http://periodicos.uesc.br/index.php/cultur/article/view/269>. Acesso em: 10 maio 2018.

PINTO, T de O. Musical difference, competition and conflict: The Maracatu Groups in the Pernambucano Carnival, Brazil. Latin American Music Reivew, Austin, v. 17, n. 2, p. 97-119, 1996. Disponível em: 〈https://www.jstor.org/stable/780346 >. Acesso em: 10 maio 2018.

PRAZERES, P. A. Maracatu Nação e a busca pela compreensão de seus aspectos religiosos: dos estudos folclóricos culturais à vivência dos jovens integrantes do arrasta ilha com o mestr e da nação do maracatu porto rico. Biblioteca Municipal Belmonte, São Paulo, jan. 2012, 18 f.

SILVA, A. C. R. da. Vamos Maracatucá: um estudo sobre os maracatus cearense. 2004. 151 f. Dissertação (Mestrado em Antropologia) - Universidade Federal de Pernambuco, Recife. 2004.

SOUZA, K. F. B. de. O consumo do espetáculo: reflexões iniciais sobre parafolclóricos de maracatu-nação ou de baque-virado. UNIrevista, v. 1, n. 2, 2006, p. 1-9. Disponível em: <https://studylibpt.com/doc/2786336/o-consumo-do-espet\%C3\%A1culo>. Acesso em: 10 jul. 2019.

SZYMANSKI, H. (Org.). A entrevista na pesquisa em Educação: a prática reflexiva. Brasília: Liber Livro, 2004.

UCELLA, O. B.; LIMA, T. O Maracatu Afrociberdélico de Chico Science e Nação Zumbi. Revista Brasileira de Estudos da Canção, Natal, n. 4, 2013, p. 11-124. Disponível em: 
<www.rbec.ect.ufrn.br/data/_uploaded/artigo/N4/RBEC_N4_A9.pdf >. Acesso em: 10 maio 2018.

WEBER, M. A "objetividade” do conhecimento nas Ciências Sociais. In: GOHN, G. (Org.). Weber. Sociologia. São Paulo: Ática, 1979. p. 79-127, 